\title{
ALLOCHRONIC SPECIATION IN FIELD CRICKETS, AND A NEW SPECIES, ACHETA VELETIS
}

\author{
Richard D. Alexander and Robert S. Bigelow \\ Museum of Zoology and Department of Zoology \\ The University of Michigan, Ann Arbor \\ and \\ Department of Entomology and Plant Pathology \\ MacDonald College, Quebec
}

Received January 25, 1960

McNeill (1889) was apparently the first investigator to recognize that the most abundant and widely distributed field cricket in northeastern North America is actually composed of two populations, one overwintering as a late instar nymph and maturing in spring and one overwintering in the egg stage and maturing in middle or late summer. McNeill also noted (1) that the adult males of the nymph-overwintering population more often occupy burrows and are characteristically more solitary and more aggressive than those of the egg-overwintering population, and (2) that the ovipositors of the females in the nymphoverwintering population are usually shorter in relation to the length of the body than those of the females in the eggoverwintering population. Later investigators, such as Blatchley (1903, 1920), Walker (1904), Criddle (1925), Urquhart (1941), Cantrall (1943), Fulton (1952), Alexander (1957), and Bigelow (1958) have corroborated and refined McNeill's observations on these two populations without materially altering his conclusions. It is surprising that in spite of the confusion in field cricket taxonomy, the relationships of this pair of populations have been fairly well understood by field biologists for about seventy years.

Prior to Fulton's work, various names had been applied to these two forms, either as binomials or as trinomials. Fulton, Alexander, and Bigelow did not separate the two populations with formal nomenclature. Fulton remained quite uncertain as to their status, being able to deal only with the southernmost fragments of their ranges in the northwestern part of North Carolina. Alexander, puzzled by the apparent identity of the two populations in song, habitat, and distribution, noted that most females: could be separated on the basis of ovipositor length, and stated (p. 592), "These two broods may interbreed in mid-summer, or possibly in fall in the southern part of their range, or it may be that they have been isolated such a short time that no noticeable differences: have yet appeared between them. Certainly more investigation is needed to clarify their relationship." Bigelow, on the basis of differences he had discovered in the developmental rates of the two. populations, and the differences in diapause stage, stated (p. 147), "The distinctive differences between these two populations are more likely to becomefurther consolidated than they are to break down through any future gene exchange. Therefore, these two populations. should be regarded as distinct species, however similar they might be morphologically."

Recently, we have pooled our information on these populations and have concluded that a more detailed discussion of their relationships, and their recognition. as distinct species, is in order. We believe that these species have become reproductively isolated through a seasonal separation of adults initially imposed by 
elimination of all but two widely separated overwintering stages in the ancestral population; there is no evidence that spatial isolation has ever existed, and no necessity for its postulation. The term "allochronic speciation" is used because it seems appropriate to include all speciation resulting initially from temporal separation (cyclic as well as linear) under "allochronic speciation" and all speciation resulting initially from spatial separation (micro-geographic as well as macro-geographic) under "allopatric speciation." "Sympatric speciation" seems to us an inappropriate label because it refers only to spatial relationships which play no more role in the process suggested here than synchrony plays in allopatric speciation.

\section{ACHETA PENNSYlvanicus}

(BURMEISTER)

\section{'The Northern Fall Field Cricket}

The name Acheta pennsylvanicus (Burmeister) has most often been used for the nymph-overwintering species, apparently because Scudder (1862) used it for a cricket which he distinguished primarily on the basis of a short ovipositor. As Blatchley (1903, p. 438) pointed out, none of the early American workers gave evidence of having seen Burmeister's types, and the original description (only a sentence) included no measurements. Examination of the types shows that the name was actually applied by Burmeister to the much more frequently collected egg-overwintering species. Measurements of types and examination of descriptions also show that Gryllus luctuosus Serville (1839), G. abbreviatus Serville (1839), Acheta nigra Harris (1841), Gryllus angustus Scudder (1862), G. neglectus Scudder (1862), and $G$. arenaceous Blatchley (1903) were all applied to the egg-overwintering species (cf. fig. 2 and Alexander, 1957), and are thus synonyms of A. pennsylvanicus (Burmeister). This is not surprising in view of the confusion among early taxonomists with regard to this group, and the much greater abundance of fall adults in collections. As shown in figure 2, a single female in Scudder's series of neglectus cotypes falls just inside the range of variation of the nymph-overwintering species in the ratio of ovipositor length to body length. Because there is no date on the label, and because this specimen cannot be assigned with any degree of confidence to the nymph-overwintering species, another specimen from this series which is obviously from the egg-overwintering species is here selected as lectotype (fig. 2) to avoid the possibility of name changes at some later date.

\section{Acheta veletis, N. SP.}

The Northern Spring Field Cricket

We designate the nymph-overwintering species as Acheta veletis in reference to its aggressive behavior. This species can be distinguished from $A$. pennsylvanicus by life history, ovipositor, and behavioral differences, and from other North American field crickets by song, distribution, morphology, and other characteristics (Alexander, 1957).

Holotype male: Collected by Alexander in Piatt County, Illinois, Sangamon Township, 17 June 1954, under a stone in a bluegrass pasture. Head, pronotum, and abdomen black; tegmina and cerci dark brown; hind femora nearly black with a reddish patch extending along the basal one-third of the outer ventral margin; other appendages dark brown or black; pronotum slightly wider anteriorly; head full and rounded, nearly as wide as widest part of pronotum; tegmina reaching to end of abdomen; hind wings reaching to basal margin of third abdominal segment anterior to base of cerci, and completely hidden by tegmina in resting position. Other distinguishing morphological characteristics are not known, except for body measurements given below and shown in figures 2-5.

Allotype female: Collected with holo- 
type; same as holotype except legs a little lighter and more reddish in color, and hind wings reaching just past basal margin of fourth abdominal segment anterior to base of cerci; ovipositor a fairly uniform dark brown.

Measurements of holotype and allotype (in millimeters, made with ocular micrometer in binocular microscope) : body length, $\hat{\sigma}, q, 22.0$; pronotal length, $\hat{\sigma}$, 4.3 , + , 4.5 ; greatest pronotal width, $\hat{\sigma}$, 6.9 , ㅇ, 6.7; head width, ô, 6.9, $9,6.4$; length of hind femur, $\delta, 11.9$, $q, 13.0$; length of tegmina, $t, 13.0, \uparrow, 12.8$; length of hind wings, $\hat{\delta}, 9.0, q, 9.5$; length of ovipostor, 14.3.

The types are located in the University of Michigan Museum of Zoology. Variations in morphology and in the calling song are discussed by Alexander (1957) under the name, Acheta pennsylvanica (Burmeister), spring brood." The different sounds of the males are described and illustrated by Alexander (1957a) under the name "mountain cricket," and appear on a record (Alexander, in press). The calling song consists of 3- to 5-pulse chirps delivered at 120-370 per minute at $85^{\circ} \mathrm{F}$. The pulse rate (wingstroke rate) at this temperature is about 25 per second. Aggressive sounds are made by increasing the chirp length, and the courtship song consists of multi-pulse, noiselike phrases delivered at about four per second with a sharp "tick" terminating each prase. There appear to be no differences between the sounds of veletis and those of pennsylvanicus, suggesting that the breeding populations of the two species have never been in contact on a large scale. No other sympatric species of Orthoptera with identical acoustical behavior are known to us.

There is no evidence of habitat separation of these species; where one is found,

1 It has since been pointed out to Alexander by Dr. A. B. Gurney (in correspondence) that Acheta is a Greek word, masculine in gender, and the feminine endings used in 1957 for $A$. firmus (Scudder) and $A$. pennsylvanicus (Burmeister) were erroneous. the other is also present, and often individual pennsylvanicus males are located in the same spots that veletis males occupied earlier in the season (Alexander, 1957; Bigelow, 1958). The only known difference in geographic distribution is that pennsylvanicus extends into Nova Scotia, while veletis apparently does not (Piers, 1918; V. R. Vickery, personal communication). These two species occur over most of the northeastern North America from southern Canada to Maryland and Virginia, down the Appalachian Mountains into western North Carolina and northern Georgia, and west across northern Alabama, Tennessee, and northern Arkansas. The western limits are not known, though they seem likely to angle northwest from about the Oklahoma-Arkansas line following the general line of the Missouri River. Both species may extend to Washington and Oregon, but we have no biological information or song records to confirm the identity of preserved specimens from the northwestern states.

\section{Evidence of Reproductive Isolation}

Morphology and behavior. The chief deterrent to recognition of veletis and pennsylvanicus as distinct species has been the absence of non-overlapping morphological differences, coupled with a lack of information as to reproductive barriers between pennsylvanicus and late surviving or occasional second-generation veletis. Nearly every worker has noted the slight overlap of adults (fig. 1), apparent because there are no nights during mid-summer when a few singing males cannot be heard.

Morphological comparisons become confusing whenever specimens from all over the geographic ranges of the species are lumped together for the evaluation of individual characters. Both species are quite variable in most of the characters we have studied, but except for a general decrease in size northward, there is little 


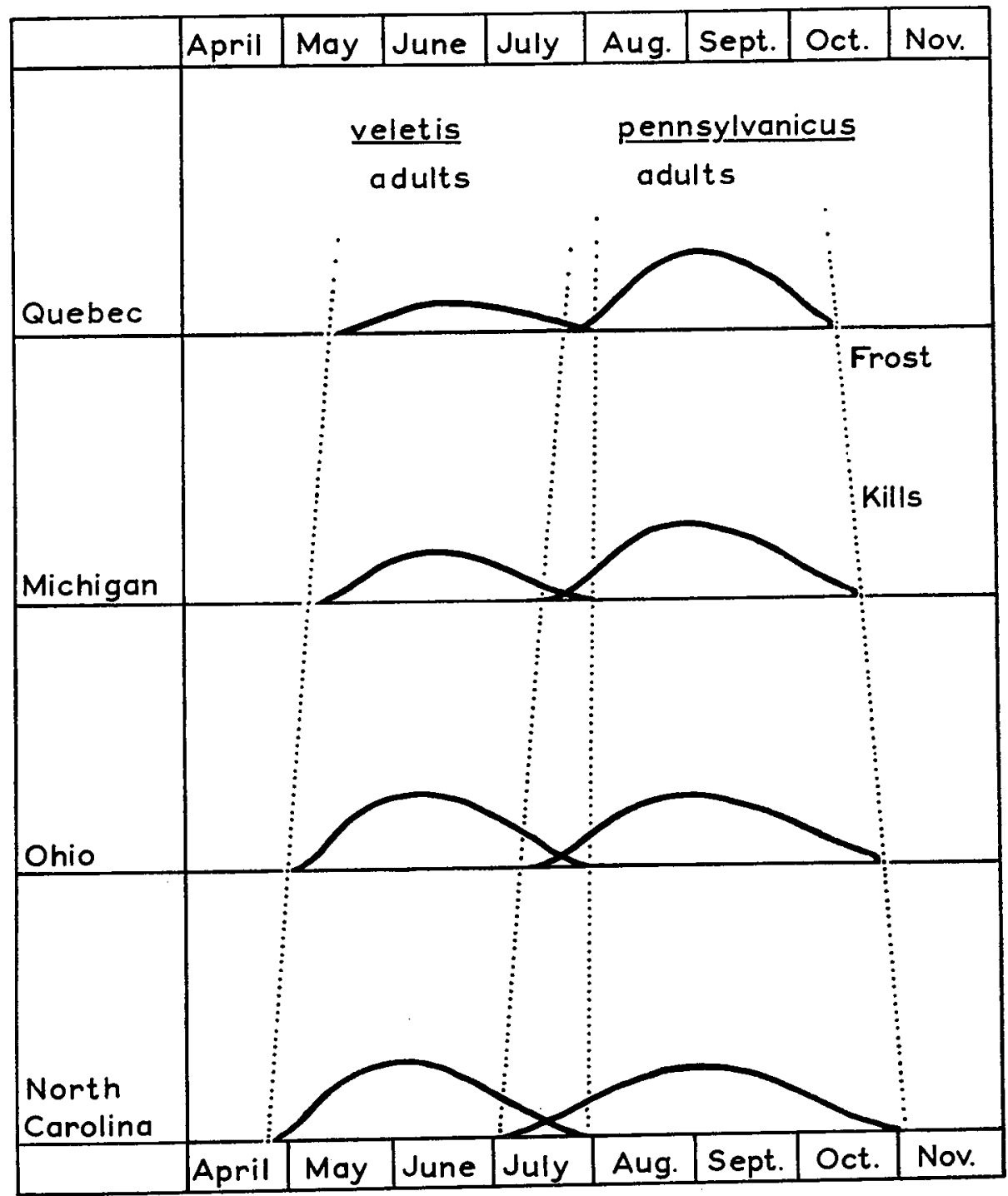

FIG. 1. A generalized diagram showing changes on a north-south plane in the relative sizes of adult populations of Acheta veletis and $A$. pennsylvanicus, and in the amount and time of overlap of adults of the two species.

indication of consistent geographic or clinal variation. Specimens from sandy areas (such as beaches around the Great Lakes and along the Atlantic Coast, and inland locations along the Illinois River and in the Kankakee Basin in Illinois and Indiana) have consistently longer ovipositors and are lighter-colored than specimens from other areas. Local popu- lations are often distinctive; for example, a veletis population with unusually pale tegmina occurs at Fort Hill in Jackson County, Ohio, and Appalachian populations of either species are apt to be uniformly large and almost entirely black. Occasional Canadian and New England specimens are even smaller than $A$. vernalis (Blatchley), although they retain 


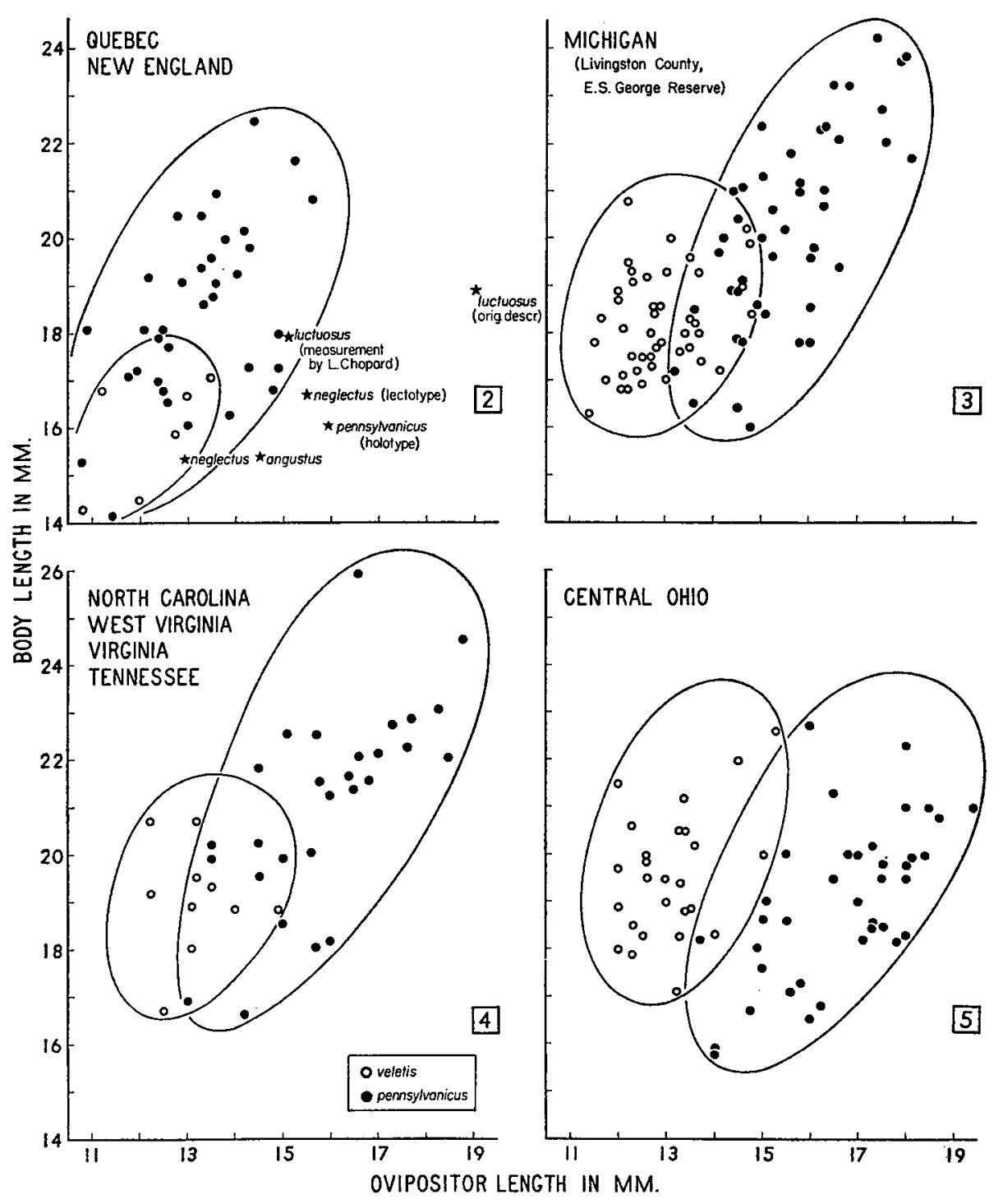

Figs. 2-5. The relationship of ovipositor length to body length in females of Acheta veletis and $A$. pennsylvanicus from various locations within their ranges.

the characteristic body conformation of veletis and pennsylvanicus.

Figures 2-5 show the relationship of body length to ovipositor length in females of the two species from the four areas considered in figure 1 . The species were separated on the basis of collection date, and all specimens available from each of the four areas involved were used, with the exception of the few taken in
July which could have been either species. Although there is overlap in each scatterdiagram, a high percentage of specimens can be separated, except on the northern border of the ranges.

Selection for longer ovipositors in pennsylvanicus has probably occurred because this species overwinters in the egg stage. It has also occurred in both species in sandy areas, and one might 
expect pennsylvanicus females to have longer ovipositors in the north than in the south. This is not the case; the pennsylvanicus females from Canada and New England have ovipositors that are shorter in relation to body length than those in any other population we have studied. Possibly the more consistent cold weather during winter in northern localities is less dangerous to overwintering eggs than the fluctuating temperatures in southern localities.

The ease with which body length is distorted by mounting techniques, and the difficulty in measuring it accurately, led us to search for other characters which would enhance the difference in ovipositor length. However, all those tested (such as femoral length, ovipositor width, and width and length of the head and pronotum) either were valueless or tended to obscure rather than to enhance the difference in ovipositor length. Since there is no reason to assume other than random error in measurement of body length, we believe it is satisfactory for the use to which we have put it. The specimens in figure 5 were pinned and dried, all in the same manner, those in figure 3 were preserved in alcohol, and both kinds of specimens were used in figures 2 and 4.

As mentioned earlier, several workers have noted a general difference between these species in gregariousness and aggressiveness, especially of the adult males, and in the tendency of older nymphs and adults to burrow or to occupy niches and crevices of various sorts. $A$. veletis has thus been described as a sedentary, solitary, aggressive, burrow-inhabiting cricket, while pennsylvanicus has been described as a gregarious cricket often found in groups and less often observed in burrows or displaying aggressive behavior. These behavioral differences appear to be fairly consistent in the field, at least in northern latitudes, and this has led to the supposition that they are genetic in origin. However, while differences in these characteristics are apparent among different species of Acheta, thev can also be produced to some degree between individuals of the same species by varying the situations in which the crickets are reared (Alexander, in prep.). Isolation increases aggressiveness and encourages burrow construction and territorial behavior, and observable differences in these respects between field-collected Michigan males of the two species have been erased in the laboratory by subsequent isolation of pennsylvanicus and crowding of veletis. Nymphs of veletis spend several months in the last three instars, when aggression and burrowing are just beginning to be evident, and are likely to disperse and become isolated. Nymphs of pennsylvanicus, on the other hand, mature directly from egg to adult in a few months, and also they do not pass through the periods of cool weather which might be partly responsible for veletis nymphs more often occupying crevices and beginning the process leading to solitary, aggressive behavior. Finally, pennsylvanicus nymphs are generally more abundant than veletis nymphs, and it is significant that the above behavioral differences have been emphasized exclusively by workers in northern latitudes where the difference in population size is most evident. At this point, we must conclude that there is no clear evidence of genetically based behavioral differences of any sort between these two species.

Diapause. Under laboratory conditions, diapause in pennsylvanicus and veletis is expressed by extensive delay in development in the egg stage and in the late nymphal instars, respectively. At $80-85^{\circ}$ F., non-diapause field cricket eggs usually hatch within three weeks; the eggs of pennsylvanicus rarely hatch in less than 60 days, and several months may be required. Under the same conditions, nondiapause nymphs usually reach maturity within two months after hatching; in veletis and other nymph-diapausing species, a small percentage matures without apparent delay, but most require several months.

The diapause difference between veletis 
and pennsylvanicus has persisted in spite of temperature, season, and light-dark ratio fluctuations in successive generations of laboratory-reared strains at MacDonald College. All of the many thousands of veletis eggs successfully incubated in the laboratory have hatched within 47 days, even at temperatures as low as $68^{\circ} \mathrm{F}$, while less than one per cent of the pennsylvanicus eggs have hatched in less than 40 days, even at temperatures as high as $82 \pm 2^{\circ} \mathrm{F}$. All veletis nymphs. were greatedly retarded at temperatures below $73^{\circ} \mathrm{F}$, and even at $82^{\circ} \mathrm{F}$, about 25 per cent were retarded. The last two or three instars persisted in some cases for three to five months.

The diapause differences between these two species appear to be fundamental. They are infallible in tagging individuals as belonging to one species or the other, they are a direct cause of temporal isolation between the species, and they may be even more directly involved in isolation if differences in the eggs and embryos are involved in the physiological incompatability demonstrated below.

Crossing experiments. It is difficult to obtain adults of veletis and pennsylvanicus at the same time; in order to do so the normal developmental rate of one species or the other must be altered in the laboratory. Both pennsylvanicus and veletis seem to require a period of low temperature conditions (in the egg and nymphal stages, respectively) if the vigor and fecundity that exist normally in the field are to be maintained. Consequently, laboratory-reared specimens must be used in controls whenever they are used in tests if the results of the crosses are to be conclusive.

The following experiments were carried out by Bigelow at MacDonald College. The adults were left together in each case until death; in the few cases of premature death, the individuals were replaced.

1. Laboratory-reared Quebec pennsylvanicus and veletis.

$\begin{array}{lcl}\text { Test } & \begin{array}{c}\text { Replica- } \\ \text { tions }\end{array} & \text { Offspring } \\ 1 \text { vel. } \sigma^{7} \times 3 \text { vel. } \% \% & 2 & \text { many } \\ 1 \text { penn. } \sigma^{7} \times 3 \text { vel. } \% \% & 3 & \text { none } \\ 1 \text { vel. } \sigma^{7} \times 3 \text { penn. } \% \% & 2 & \text { none } \\ 1 \text { penn. } \sigma^{7} \times 3 \text { penn. } \% \text { \% } & 2 & \text { many }\end{array}$

2. Field-collected Quebec pennsylvanicus and laboratory-reared Quebec veletis.

$\begin{array}{lcl}\text { Test } & \begin{array}{c}\text { Replica- } \\ \text { tions }\end{array} & \text { Offspring } \\ 6 \text { penn. } \sigma^{7} \sigma^{7} \times 12 \text { penn. } \% \% & 1 & \text { many } \\ 6 \text { penn. } \sigma^{7} \sigma^{7} \times 12 \text { vel. } \% q & 1 & \text { none } \\ 6 \text { vel. } \sigma^{7} \sigma^{7} \times 12 \text { penn. } \% क & 1 & \text { none } \\ 6 \text { vel. } \sigma^{7} \sigma^{7} \times 12 \text { vel. } \% \text { \% } & 1 & \text { many }\end{array}$

3. Field-collected veletis from Danbury, North Carolina, Culpepper, Virginia, Frederick, Maryland, and Quebec, and laboratory-reared pennsylvanicus from Quebec and Dutchess County, New York. Every combination of veletis individuals from different localities was tested, and every test produced many offspring; the same was true of pennsylvanicus matings involving Quebec $\times$ New York individuals. No offspring were produced in the two crosses attempted: 2 penn. of $\hat{0}$ $(\mathrm{NY}) \times 3$ vel. $q \&(\mathrm{Va})$ and 3 penn. $\delta$ o $(\mathrm{NY}) \times 4$ vel. $q$ q $(\mathrm{Q})$.

Eggs were laid frequently in the crosses listed above, copulation was observed once between a pennsylvanicus female and a veletis male, and the spermatheca of a single veletis female examined was found to contain pennsylvanicus sperm. Clearly, some effective barrier exists; if hybrids are present in the field they must be exceedingly rare, and actual exchange of genes is even less likely.

\section{Allochronic Speciation}

In the vast majority of cases, speciation in sexually reproducing animals probably takes place as outlined by Mayr (1942, 1947) and others. Populations become geographically isolated and diverge through differential selection imposed by their respective environments, and additionally through the accumulation of chance differences in mutations and recombination. If these differences happen 
to make the two populations physiologically, morphologically, or behaviorally incompatible, or if they merely make exchange of genetic materials sufficiently deleterious prior to the resumption of geographic contact, then the two populations are irrevocably isolated. With resumption of geographic contact, the resultant interaction between such newly formed species should operate to maximize the efficiency of their isolation and enhance the accelerating and re-inforcing factors operative in their continuing divergence.

Basic to this process is the presence of an extrinsic barrier to gene flow between the two populations with at the same time a sufficiently broad avenue of gene flow within each population to allow consolidation of characteristics leading (eventually) to incompatibility. In sexually reproducing animals these requirements largely eliminate (with certain exceptions-cf. Dethier, 1954) the possibility of speciation along the lines of ecological divergence, which is essentially speciation in the absence of an initial extrinsic barrier to gene flow (Mayr, 1947).

One is faced with certain problems in attempting to reconstruct the evolution of veletis and pennsylvanicus on the basis of previous allopatry. First, there is no evidence that these species have ever been allopatric; indeed, their wide range, their apparent identity in ecological distribution, and the fact that their geographic limits appear to coincide everywhere but in the north tend to support the opposite suggestion--that they have never differed in geographic distribution more than they do today. The fact that only pennsylvanicus occurs in Nova Scotia appears to be more likely a result of the difference in overwintering stage than a reflection of difference in distributional history, and this is supported by the north-south change in the relative abundance of the two species (fig. 1), which indicates that veletis nymphs are less likely to survive severe winters than pennsylvanicus eggs.
If one postulates that veletis and pennsylvanicus acquired their present incompatability while geographically separated, he is left with the problem of how they developed such widely different overwintering stages without diverging in other ecological respects. The difference in breeding season cannot easily be explained as a result of interaction after hybridization had become disadvantageous, for the identity in all phases of acoustical behavior and the ability to cross-copulate strongly suggest that the breeding populations of the two species have not been in significant contact since their separation. Further, the lack of difference in ecological distribution reduces the likelihood that the difference in breeding season arose in association with other environmental factors favoring the presence of particular stages at particular times.

But extrinsic barriers need not involve geographic or spatial separation. Bigelow (1958) discussed the possibility that veletis and pennsylvanicus have speciated without geographic separation through a seasonal isolation of breeding populations. All of the information we have been able to gather with respect to the relationships of these species and the pertinent characteristics of related Orthoptera has reinforced this hypothesis. Three relatively simple steps are involved: (1) the repeated elimination during successive winters of all stages but late juveniles and eggs, with a concomitant reduction or elimination of gene flow between the resulting populations, (2) subsequent increases in the winter-hardiness of the two overwintering stages, culminating in the development of obligate diapauses and (3) the eventual appearance of reproductive incompatibility.

The first step in the above sequence is obviously the most important one, and the one which must be clearly understood if this process can be accepted. How can a species be divided into two populations which exchange genes on a very much reduced basis or not at all, simply by a 
differential elimination of overwintering stages? How could this sort of separation persist long enough to allow consolidation of intrinsic isolating mechanisms, and in what sorts of climates could such a phenomenon take place?

An animal susceptible to splitting through the kind of allochronic speciation suggested here for veletis and pennsylvanicus would be required to possess the following characteristics : (1) a consistent developmental rate producing fewer than two generations per year, (2) a narrow breeding season or a short adult life, and (3) a duality in winter-hardiness, with the two stages involved widely separated on the life history cycle. All of the approximately 85 species of native Gryllidae and Tettigoniidae in northeastern North America possess the first two of these characteristics, and the eight species of Gryllinae there possess all three. North of the 38th parallel, none of these 85 species produces more than a single generation per year. The adults live about six weeks, or less than half the available season, and they generally mature together, producing for each species either a spring or a fall adult population. Only two overwintering stages are represented-late juveniles and eggs-and no species overwinters north of about the 38th parallel in more than a single stage, with the exception of the European house cricket, Acheta domesticus, living in artificially warmed situations, and the possible exception of the ant nest inhabitant, Myrmecophila pergandei. Two cone-headed grasshoppers, Pyrgocorypha uncinata and Neoconocephalus triops, overwinter after their final molt, but even these "adults" must be considered immature, for sexual behavior does not begin until the following spring, even in adults kept in the laboratory. Seventy species overwinter as eggs and the rest as late juveniles; all of the latter are burrowing crickets except for the two cone-headed grasshoppers, which apparently spend the winter deep in the bases of clumps of thick vegetation, and which reach northward only to the vicinity of the 38th parallel. One southern field cricket, Acheta firmus, reaches to about the 38th parallel and overwinters as both eggs and late instar nymphs there, while breeding more or less continuously and overwintering in all stages farther south.

Duality in winter-hardiness is obviously not unusual in Orthoptera, and it would appear that the burrowing behavior which begins in late juvenile crickets is closely associated with the ability to overwinter. Evidently, nymphs are somewhat less winter-hardy than eggs, even after diapause has appeared, for veletis is the most northern nymph-overwintering orthopteran in North America; the other two strictly nymph-overwintering field crickets, $A$. vernalis and $A$. fultoni, which incidentally are much less active burrowers than veletis, reach only to the vicinity of the 40th parallel.

All of the native Gryllidae and Tettigoniidae in northeastern North America exhibit obligate diapauses in the overwintering stage, completing development only after considerable delay or after passing through a cold period. These diapauses have an important function in addition to their association with winterhardiness; they synchronize the appearance of the short-lived adults and are thus responsible for producing a definite breeding season which can be relatively short and yet highly efficient. The coneheaded grasshoppers which overwinter as adults and are not triggered into sexual behavior until spring are important examples. It seems a fair assumption that selection for diapause in connection with synchronizing the appearance of adults in climates such as prevail in northeastern North America is at least as intense as selection for diapause in connection with winter-hardiness.

The nymph-overwintering Gryllinae, including species of Miogryllus and Anurogryllus as well as Acheta, almost 
inevitably diapause in the second instar from adulthood. The reasons for this rather precise limitation are not clear, but nymphal diapause has certainly appeared more than once in these crickets, suggesting that this particular stage is unusually susceptible to its development. This is important information, for it strengthens our speculation that nvmphal diapause must have appeared independently many times across the range of the nymph-overwintering population that gave rise to veletis, as well as egg diapause probably many times within the egg-overwintering population that gave rise to pennsylvanicus. There is no reason to believe that this could not have happened while a considerable amount of gene flow was still going on between the ancestral populations of veletis and pennsylvanicus; whenever and wherever diapause appeared, either in veletis nymphs or in pennsylvanicus eggs, it surely decreased to a great extent the likelihood of subsequent amalgamation of the two populations.

We would hypothesize the evolution of veletis and pennsylvanicus as follows. The ancestral population probably inhabited an area of mild winters and bred more or less continuously there. Either an increase in the rigorousness of winters or the isolation of a northern segment of this population (or some combination of such events) produced a population in which all stages but late juveniles and eggs were decimated during each winter. The eggs survived initally because they were buried in the soil, and the nymphs survived initially because of their beginning to actively burrow about three instars from adulthood. We might expect that overwintering nymphs would frequently mature before spring under these conditions, but adults which matured late in the fall would be unlikely to survive until spring because of the short adult life and the tendency of the adults to be active in connection with sexual behavior.
A reasonably consistent developmental rate would now produce a population of spring adults and a population of fall adults. There would undoubtedly be a reduction in gene flow between these two populations, and this condition could persist indefinitely under proper climatic conditions in the absence of genetic differences between the two populations.

Under these conditions, the appearance of diapauses increasing winter-resistance in the already resistant stages and synchronizing the appearance of adults in spring and fall would be advantageous to each of the two partially isolated populations. Wherever such diapauses appeared and were retained, they would further reduce gene flow between the two populations, at the least through emphasizing the appearance of adults only in spring and in fall. The gradual consolidation of diapause in the two different overwintering stages could lead only to more stringent isolation, eventually allowing development of the intrinsic isolating mechanisms present today. As noted, the diapauses themselves may involve morphological or physiological characteristics which produce incompatability. Hybridization at any time during the above sequence would probably be disadvantageous, early in the sequence simply because it would tend to occur in the middle of the season and thus to produce individuals that were likely to be in the wrong stages at the onset of winter, and late in the sequence because almost any manner of inheritance of diapause characteristics would likely cause hybrids to be at a disadvantage additional to that accruing from being in the wrong stage at the wrong time.

The beach cricket, Acheta firmus, is especially important in this reconstruction, not only because it illustrates how the process could take place, but also because it may actually be involved in this particular case. This species occurs along the Gulf Coast and the Atlantic Coast from Louisiana to Delaware. In 
southern Florida, it appears to breed more or less continuously; in the northern parts of its range it becomes an egg-overwintering species producing a single generation per year, but with a few individuals there getting "out of step with the main population" (Fulton, 1952, p. 289), overwintering as juveniles and maturing in May and June. Not only does this species illustrate duality in winter-hardiness without significant nymphal dispause, but should a northern population become isolated in the area where the species now overwinters only as eggs and as late juveniles, then the separation of that northern population into two species according to the process suggested here for veletis and pennsylvanicus would be very easy to visualize. It is quite possible that this is exactly what did happen in the past, and that firmus represents the southern remnant of the ancestral population which also gave rise to veletis and pennsylvanicus. Today, firmus is clearly more closely related to veletis and pennsylvanicus than any other North American field cricket, showing close similarity in acoustical behavior, morphology, and developmental rate. The chief difference in morphology among these species is that firmus females have very long ovipositors, undoubtedly evolved in association with the beach habitat.

Allochronic speciation as outlined above is a simple and reasonable hypothesis, and the only one which satisfactorily explains all facets of the present characteristics and relationships of veletis and pennsylvanicus. It is doubtful that the possibility of allopatric speciation could ever be completely ruled out, but the evidence suggests that geographic isolation is both unlikely and unnecessary in this particular case.

\section{Discussion}

Speciation through initial seasonal or other cyclic isolation is not a new idea, but the actual process by which it might occur has not previously been outlined in detail for a particular group of animals. Emerson (1949) summarized most of the investigations dealing with this possibility, and more recently Ghent and Wallace have hypothesized speciation through a seasonal separation caused by overwintering in both egg and pupa in sawflies (Hymenoptera). The greatest problem has been in visualizing the initial step; in the process as suggested here, no genetic difference is required, either for the initial separation of populations or for the long-time maintenance of their separation.

A great deal of biological information will have to be acquired before the significance of temporal isolation in helping to account for the prolificness of speciation in insects can be determined. A cyclic phenomenon similar to that discussed here occurs in many insects when populations of species in which the life cycle requires more than a year become isolated by maturing on different years. This happens in many cicadas, most notably between sympatric broods of periodical cicadas, and between those species with 17-year and 13-year life cycles. It may be a more common occurrence than is suspected in other insects as well. Gabbutt (1959), for example, found that Nemobius sylvestris (Bosc.), a European ground cricket, has a two-year life cycle, each individual diapausing as an egg one year and as a nymph the next year. The only possibility of gene exchange between populations maturing on different years is through stragglers, and in cicadas, in which the presence of adults can easily be detected because of their loud songs, stragglers are known to be extremely unusual. In such cases, temporal isolation can be as effective as complete allopatry.

The characteristics of animals susceptible to allochronic speciation are obviously not restricted to the Orthoptera; rather they are widespread among invertebrates in temperate climates, especially among 
metamorphosing insects. Without the hypothesis of allochronic speciation we would continue to be puzzled by the hundreds of cases in which dichotomy in overwintering stages has become established within groups of closely related species. Such dichotomies have surely arisen many times without speciation, either through the chance appearance of greater winter-hardiness in an unusual stage or through selection for the appearance of the breeding population during a particular season. But when two closely related, sympatric species are found to overwinter in stages which are widely separated on the life history cycle, when there is no evidence for earlier allopatry, and when the two species also maintain brief, non-overlapping periods of reproductive maturity without evidence of previous interaction with respect to characters involved in sexual selection, then it would appear that the possibility of allochronic speciation should not be ruled out without careful study.

\section{Summary}

Analysis of what has seemed to be a single species of field cricket, abundant and widely distributed in northeastern North America, shows that it is actually composed of two closely related species which are distinguished as follows: (1) they diapause only in the late nymphal instars and in the egg stage, respectively, (2) they are unable to produce viable eggs in controlled crossing experiments in the laboratory, and (3) most females from the same locality can be separated by ovipositor length. Breeding populations of these two species are seasonally isolated because of the difference in overwintering stage and the short adult life of four to eight weeks. Ecologically and geographically the two species have always been found together, with the exception that Acheta pennsylvanicus (Burmeister), the egg-overwinterer, occurs in Nova Scotia, while $A$. veletis, n. sp., the nymph-overwinterer, does not. All of the communicative sounds of the two species appear to be identical, indicating that there has been no interaction with respect to characters involved in sexual selection. It is suggested that these species have become isolated through a seasonal separation of breeding populations imposed by a duality in winter-hardiness originally due to the deposition of the eggs below the soil surface and the burrowing of late juveniles. This initial isolation is then believed to have been re-inforced by the appearance of genetically-based diapauses which not only increased winter-hardiness but also aided in synchronizing the appearance of the adults. The term "allochronic speciation" is applied because of the role of temporal isolation; it is suggested that various forms of cyclic isolation may have been important factors in initiating speciation among insects in temperate climates.

\section{ACKNOWLEDGMENTS}

This study was supported by grants awarded to Alexander by the Horace $\mathrm{H}$. Rackham School of Graduate Studies of The University of Michigan, and to Bigelow by The National Research Council of Canada. We are indebted to Drs. Theodore H. Hubbell, Thomas E. Moore, and Irving J. Cantrall, and to Mr. Kenneth C. Shaw, all of The University of Michigan Museum of Zoology, for suggestions concerning the manuscript. Dr. Edward S. Thomas of The Ohio State Museum has allowed us to use excerpts from his extensive notes concerning the distribution and abundance of Orthoptera. The specimens from the E. S. George Reserve, Livingston County, Michigan (fig. 3) were all collected by Dr. Irving J. Cantrall.

\section{Literature Cited}

Alexander, R. D. 1957. The taxonomy of the field crickets of the eastern United States (Orthoptera: Gryllidae: Acheta). Ann. Ent. Soc. Amer., 50 (6) : 584-602, 19 fig., 1 tab. 
1957a. Sound production and associated behavior in insects. Ohio Jour. Sci., 57 (2) : 101-113, 13 fig., 1 text fig.

Alexander, R. D. (in press). Sound communication in Orthoptera and Cicadidae. (In A. I. B. S. Symposium Series, Animal Sounds).

Alexander, R. D. (in prep.) Aggressiveness, territoriality, and sexual behavior in field crickets.

Bigelow, R. S. 1958. Evolution in the field cricket, Acheta assimilis Fab. Canadian Jour. Zool., 36 (1958) : 139-151, 3 tab.

Blatchley, W. S. 1903. The Orthoptera of Indiana. 27th Ann. Rept. Ind. Dept. Geol. and Nat. Resources: 123-471, 122 fig.

- 1920. Orthoptera of Northeastern America. 784 pp., 246 fig. Indianapolis, Ind., The Nature Publ. Co.

Cantrall, I. J. 1943. The ecology of the Orthoptera and Dermaptera of the George Reserve, Michigan. Univ. Mich. Mus. Zool. Misc. Publ., 54: 1-182, 3 fig., 2 maps, 16 tables, $10 \mathrm{pl}$.

Cridde, N. 1925. Field crickets in Manitoba. Canadian Ent., 57 (4) : 79-84.

Dethier, V. G. 1954. Evolution of feeding preferences in phytophagous insects. EvolUTION, 8 (1) : 33-54, 1 fig.

Emerson, A. E. 1949. Ecology and Isolation. (Pp. $605-630$ in Principles of Animal Ecology by Allee et al., xii +837 pp., 263 fig., 54 tables. Philadelphia and London: W. B. Saunders Co.).

Fulton, B. B. 1952 . Speciation in the field cricket. Evolurion, 6 (3) : 283-295, 4 fig.

Gabbutt, P. D. 1959. The bionomics of the wood cricket, Nemobius sylvestris (Orthoptera: Gryllidae). Jour. Animal Ecol., 28 (1) : $15-42$.

Ghent, A. W. and D. R. Waldace. 1958. Oviposition behavior of the Swaine jackpine sawfly. Forest Science, 4 (3) : 264-272, 2 fig., 1 table.
Harris, T. W. 1841. A treatise on some of the insects injurious to vegetation. Orange Judd and Co., New York. xi +640 pp., numer. fig.

Hebard, M. 1931. A revision of the North American species of the genus Myrmecophila (Orthoptera: Gryllidae: Myrmecophilinae). Trans. Amer. Ent. Soc., 46: 91-111, 1 fig.

MAYR, E. 1942. Systematics and the Origin of Species. New York: Columbia Univ. Press. xiv +334 pp., 29 fig., 14 tables. 1947. Ecological factors in speciation. Evolution, 1 (4) : 263-288, 1 fig.

MCNeILL, J. 1889. Notes upon Gryllus and Oecanthus. Entomologica Americana, 5: 101-104.

Pifrs, H. 1918. The Orthoptera (cockroaches, locusts, grasshoppers and crickets) of Nova Scotia; with descriptions of the species and notes on their occurrence and habits. Trans. Nova Scotia Inst. Sci., 14 (3) : 201-356, 4 pl., 27 fig.

ScudDER, S. H. .1862. Materials for a monograph of the North American Orthoptera, including a catalogue of the known New England species. Bost. Jour. Nat. Hist., 7 : 409-480.

- 1877. New forms of saltatorial Orthoptera from the southern United States. Proc. Bost. Soc. Nat. Hist., 19: 35-41.

- 1902. The species of Gryllus found in the United States east of the Sierra Nevadas. Psyche, 9 (309) : 291-296.

Serville, M. A. 1839. Histoire naturelle des insectes Orthoptères (dans les suites à Buffon). Paris, Roret., 1-776 pp., 22 fig.

URQUhART, F. A. 1941. The Blattaria and Orthoptera of Essex County, Ontario. Contrib. Roy. Ontario Mus. Zool., 1-32 pp., 4 fig.

WALKER, E. M. 1904. The crickets of Ontario. Canadian Ent., 36 (7) : 181-188. 